\title{
A Normatização Da Destinação Dos Lucros
}

\author{
The Regulation Of Net Profit Distribution
}

\author{
Tiago André Guesser \\ Tiago.guesser@hotmail.com \\ UFSC
}

\author{
Marcos Laffin \\ marcoslaffin@gmail.com \\ UFSC
}

\begin{abstract}
Resumo
A destinação dos lucros é uma das mais importantes discussões na gestão das empresas por envolver dois aspectos: continuidade das operações e satisfação dos acionistas. De certa forma, a legislação societária considera esses importantes fatores ao prever a possibilidade de formação de reservas e a garantia de um mínimo a ser destinado aos sócios. Nesse contexto, esta pesquisa - de natureza exploratória - realizada por meio das Demonstrações Contábeis de 17 empresas do segmento de Construção Civil da BM\&FBOVESPA, busca identificar o cumprimento dos dispositivos legais de destinação dos resultados referente aos exercícios de 2009, 2010 e 2011. Os resultados evidenciam que a maiorias das empresas respeita o limite estabelecido na legislação para a constituição de reservas e destinação de dividendos em pelo menos dois exercícios; e que a quase totalidade das companhias cumpre os dispositivos legais de acumulação de saldo nas contas. Verifica-se ainda, que apenas uma das empresas não respeitou a norma que impede a manutenção de saldo credor na conta de Lucros Acumulados.
\end{abstract}

Palavras-chave: Destinação de Lucros. Lei 11.638/07. Lucros Acumulados. Dividendos. Reservas de Lucro.

\begin{abstract}
Net profit sharing has been one of the most important discussed issues in the management of enterprises because it involves two factors, the continuation of the operations and the satisfaction of the shareholders. To a certain extent, the corporation legislation takes into account such factors when it foresees the possibility of establishing profit reserves and guarantees a minimum participation of the stockholders in the companies' profits. In this context, the present research - of an exploratory nature - , undertaken through the examination of the financial statements of 17 companies listed on BM\&FBOVESPA under the label of building, aims to verify whether the legal norms concerned with profit distribution have been obeyed in the years of 2009, 2010 and 2011. The results show that the majority of the companies obeyed the limits imposed by the legislation in what concerns profit reserves and profit sharing by stockholders in at least two fiscal years, and that almost all the companies under scrutiny followed what the law says concerning the amount to be left in the accounts. It was also noticed that only one of the enterprises did not respect the norm which prohibits any retained earnings after the profit distribution.
\end{abstract}

Key-words: Net Profit Sharing. Act n. 11.638/07. Retained Earnings Account. Dividends. Profit Reserves.

Artigo recebido em: 10.08.2012; Aceito em: 29.08.2012

\section{INTRODUÇÃO}


Sob a ótica financeira, a constituição de uma companhia representa uma forma alternativa de aplicação de recursos excedentes. Ao realizá-la, os investidores; representados na pessoa dos sócios, abrem mão de outras formas possíveis de investimento, julgando que por meio do desenvolvimento das atividades previstas para a companhia poderão obter rentabilidade no mínimo igual às demais alternativas do mercado.

No caso das companhias, tal rentabilidade é obtida através da diferença positiva entre as receitas auferidas e os recursos despendidos para a sua obtenção; isto é, através do lucro. Todavia, conforme destacam Padoveze, Frezatti e Benedicto (1994, p. 3); esse não é o objetivo maior da organização. Os autores assinalam que a empresa "deve ter por objetivo máximo o cumprimento de sua missão, posto que esta se constitui na verdadeira razão de sua existência"; estando representada pela linha de atividades que a mesma pretende seguir.

Sob essa ótica, o lucro não é a única finalidade da empresa, mas sim um objetivo consorciado à continuidade de mesma. Contudo, o mesmo é elemento fundamental para a empresa no ambiente no qual se insere e para com todos os que com ela se relacionam (PADOVEZE, FREZATTI, BENEDICTO, 1994); e sua utilidade está vinculada a duas finalidades específicas: remuneração direta ao investidor - por meio dos dividendos, e reinvestimento na própria companhia.

A distribuição dos lucros disciplinada na forma do capítulo XVI da lei $n^{\circ} 6.404 / 76$, ao prever diferentes possibilidades de constituição de reservas e estabelecer valor mínimo de destinação para dividendos, assegura a presença de dispositivos legais significativamente importantes quando da destinação do resultado: a satisfação dos acionistas e a continuidade das atividades. Tal continuidade é verificada por meio da formação de reservas com vistas à expansão e prevenção de situações adversas futuras da empresa; bem como da integridade do capital, garantida pela formação da reserva legal.

Cumpre ainda ressaltar o fato de que, além de prever a formação de reservas e a distribuição para fins de dividendos; a lei das Sociedades por Ações exige ainda, a completa destinação do lucro durante o exercício. Sobre essa questão, Iudícibus et al (2003 apud SALOTTI e SANTOS, 2009, p. 67) explicam que "desde 1986 há a determinação legal que obriga a destinação da totalidade dos lucros." Mais recentemente, e visando o cumprimento de tal determinação; a Lei $n^{\circ}$ 11.638/07, apontada como responsável pelas mais profundas mudanças na contabilidade societária brasileira nos últimos trinta anos (PONTE et al, 2010), acabou por impedir a possibilidade da existência de saldo credor na conta de Lucros Acumulados (MIOLA et $a l, 2011)$, outrora integrante do grupo do Patrimônio Líquido.

Face ao acima exposto, e admitindo-se ainda o processo de convergência às normas internacionais de contabilidade, esta pesquisa se desenvolve a partir da seguinte pergunta: Que procedimento tem sido adotado pelas Cia. Abertas no que se refere à destinação dos lucros? Com base nessa questão, estabeleceu-se como objetivo geral analisar o cumprimento por parte das companhias listadas no segmento de Construção Civil da BM\&FBOVESPA, dos dispositivos legais de destinação dos resultados referente aos exercícios de 2009, 2010 e 2011.

Para a consecução do objetivo proposto, estabeleceram-se como objetivos específicos: (i) verificar o cumprimento à legislação no que tange ao limite permitido para a destinação; (ii) averiguar se as empresas estão respeitando o limite legal de saldo acumulado nas contas recebedoras do lucro do exercício; (iii) analisar o cumprimento à norma que impede a existência de saldo credor na conta de Lucros Acumulados. 
A relevância deste estudo justifica-se, na medida em que a pesquisa permite $\mathrm{o}$ conhecimento sobre a observância da legislação para a destinação dos lucros. A importância do presente trabalho também se justifica pelo fato de estar sendo realizado a partir de um segmento empresarial que esteve bastante aquecido nos últimos anos em função das políticas públicas para a distribuição de renda e da preparação para eventos esportivos a se realizarem em futuro próximo.

\section{Conceito de Lucro e Formas de Destinação}

É consenso na literatura contábil que o lucro constitui-se na sobra obtida pela empresa em suas operações e que está à disposição dos proprietários. Na visão de Facci e Moribe (2000) o lucro representa a diferença positiva obtida pela empresa, conquanto que sejam mantidos os ativos capazes de produzir novos resultados positivos ao serem explorados em sua capacidade de gerar recursos.

Dessa forma, ao final do exercício social os proprietários decidem sobre o destino dado a essa sobra; que, em grandes linhas, será a opção pela retenção, assegurada na figura das reservas de lucros (SALOTTI e SANTOS, 2009); ou ainda, pela opção de distribuição aos sócios por meio dos dividendos, como forma de remuneração dos valores por eles investidos (PADOVEZE, FREZATTI, BENEDICTO, 1994). Vale ressaltar que essa destinação, além de considerar a opinião do sócio/investidor; deve também observar os aspectos legais atualmente fundamentados na Lei das Sociedades por Ações - Lei $n^{\circ}$. 6.404/76 - recentemente modificada em virtude do processo de Convergência às Normas Internacionais; bem como as suas alterações.

Com o processo de convergência e harmonização contábil visualiza-se maior quantidade e qualidade ao conjunto de dados disponibilizados nos demonstrativos contábeis, em decorrência da alteração de princípios contábeis aprimorando a informação (SANTOS et al, 2010). Convém salientar que a obrigatoriedade de aplicação das novas práticas, principalmente aquelas advindas com a Lei $\mathrm{n}^{\circ} 11.638 / 07$, deu-se apenas a partir do ano de 2010; sendo exigida para fins de comparação, a elaboração das demonstrações contábeis do exercício anterior ao da adoção das normas.

\subsection{Destinação dos Resultados posteriores às Alterações na Lei 6.404/76}

A Lei 11.638/07, no intuito de modernizar e harmonizar as disposições da lei societária em vigor com os princípios de contabilidade e melhores práticas internacionais, alterou e revogou diversos dispositivos; especialmente no que tange aos demonstrativos contábeis das empresas (FURUTA, BISPO, VIEIRA, 2010).

Ponto que tem gerado controvérsias, a eliminação da conta de Lucros Acumulados no Balanço Patrimonial resultante deste processo, visa garantir a completa destinação do resultado; seja para dividendos ou para as reservas de lucros. Salotti e Santos (2009) argumentam, no entanto, que esta exigência de completa destinação do resultado pode ser encontrada em normas anteriores à Lei $n^{\circ} 11.638 / 07$, como é o caso da Instrução $\mathrm{CVM} \mathrm{n}^{\mathrm{o}}$ 59/86 e na Lei $\mathrm{n}^{\mathrm{o}}$ 10.303/01. Em estudo publicado em 2009, os autores relatam que "ainda há empresas com saldo em Lucros Acumulados, mas com tendência de queda: o percentual de empresas apurado foi de $34 \%$ em 2001, e caiu para $14 \%$ em 2005." Tal queda é atribuída às alterações na Lei $\mathrm{n}^{\circ}$ 6.404/76 advindas da Lei $\mathrm{n}^{\circ}$ 10.303/01. Convém ressaltar que a conta de Lucros Acumulados, conforme mencionado no item 42 do Pronunciamento Contábil CPC 13, que trata da adoção inicial da Lei $\mathrm{n}^{\mathrm{o}} 11.638 / 07$ e da Lei $\mathrm{n}^{\circ} 11.941 / 09$, passa a ter natureza absolutamente transitória e não deverá ser excluída do plano de contas; visto que servirá de 
contrapartida às reversões das reservas de lucros e às destinações do resultado. A Lei $\mathrm{n}^{\circ}$ 6.404/76 apresenta como reservas de lucros: Reserva Legal, Reserva Estatutária, Reserva para Contingências, Retenção de Lucros e Reserva de Lucros a Realizar. Posteriormente, com as recentes alterações na Lei 11.638/07 foi também criada a Reserva de Incentivos Fiscais.

\subsubsection{Reserva Legal}

A reserva legal constitui-se numa reserva de lucro que, conforme $\S 2^{\circ}$ do art. 193 da Lei $n^{\circ}$ 6.404/76, é destinada a assegurar a integridade do Capital Social, e tem sua utilização vinculada à compensação de prejuízos ou ao aumento do Capital Social. Dessa forma, conforme Iudícibus, Martins e Gelbcke (2010 apud MIOLA et al, 2011) tal reserva é instituída para dar proteção ao credor. A respeito da sua constituição, o artigo legal acima mencionado prevê que essa seja feita antes de qualquer outra destinação no montante equivalente a $5 \%$ do lucro líquido do exercício. O limite máximo previsto para tal, equivale a $20 \%$ do Capital Social. A lei societária prevê ainda outra possibilidade em que a conta poderá deixar de receber parte do lucro obtido: "A obrigatoriedade de constituição da reserva legal deixa de existir no exercício em que o saldo da mesma, acrescido ao montante das Reservas de Capital elencadas no $\S 1^{o}$ do artigo $n^{\circ} 182$ da mesma lei, exceder de 30\% (trinta por cento) do Capital Social."

\subsubsection{Reserva Estatutária}

Conforme a Lei $\mathrm{n}^{\circ}$ 6.404/76, as reservas estatutárias são aquelas que poderão ser constituídas, conquanto estejam previstas no estatuto da companhia e respeitem os seguintes quesitos: i) indicação, precisa e completa, de sua finalidade; ii) fixação de critérios para determinar a parcela anual dos lucros líquidos que serão destinados à sua constituição; e iii) estabelecimento do limite máximo de constituição. Dessa forma, não há um limite legal expresso para a sua constituição, uma vez que o mesmo deverá ser estabelecido pela própria companhia.

Entretanto, conforme enunciado pela Instrução CVM n ${ }^{\circ}$ 59/86, a necessidade de especificação no estatuto, do valor que cabe a essa reserva constitui-se de uma limitação legal; visando primordialmente a não possibilidade de prejuízos ao pagamento do dividendo mínimo obrigatório. A Instrução Normativa destaca ainda que "[...] tais reservas são normalmente criadas para atender características operacionais específicas não sendo admitida a criação para finalidades já atendidas por outras reservas[...]".

\subsubsection{Reservas para Contingência}

Contingência, conforme definido por Santos e Schmidt (2009 apud MIOLA et al, 2011, p. 4) se refere a "perdas futuras decorrentes de cheias, secas, geadas, granizos e outros fenômenos naturais que podem ocorrer onde se localizam estoque ou instalações da empresa[...]". Assim sendo, a legislação societária prevê através do Art. 195 da Lei no 6.404/76, a possibilidade, caso a administração assim o desejar, de destinar parte do lucro líquido visando à compensação futura de perdas prováveis cujo valor possa ser estimado. Para tanto, deverá haver a justificação da constituição dessa reserva, bem como as causas das perdas previstas.

Note-se, assim, a necessidade expressa de estimativa do valor da perda, o que diferencia esta reserva da provisão para contingências. A referida lei prevê ainda, a reversão do 
valor constituído no exercício de ocorrência da perda, ou a cessão das razões que justificaram a sua constituição.

\subsubsection{Reserva de Incentivos Fiscais}

Incluída pelo Artigo 195 da Lei $\mathbf{n}^{\mathbf{0}} \mathbf{1 1 . 6 3 8 / 0 7}$, essa reserva destina-se a abrigar a parcela do lucro líquido decorrente de doações ou subvenções para investimentos. Ainda de acordo com o Artigo 195-A da Lei 6.404/76, há a possibilidade de constituição dessa reserva quando a mesma for proposta pelos órgãos da administração e aprovada pela assembléia geral. Merece destaque o fato de que os valores a ela destinados poderão ser deduzidos da base de cálculo do dividendo obrigatório.

\subsubsection{Retenção de Lucros}

Conforme destacado por Salotti e Santos (2009, p.68) configura-se a retenção de lucros numa "decisão que as empresas tomam visando ao financiamento de suas operações futuras". Corroborando esta afirmação, Padoveze, Frezatti e Benedicto (1994, p. 7) destacam que, "caso os acionistas optem por reduzir o nível de financiamentos poderá haver retenção de volumes de lucros maiores do que os previstos". Tal situação, segundo os mesmos, também pode ocorrer em consequência da opção pela expansão da capacidade da empresa. Os autores ainda observam o fato de que, em regra geral; a retenção de capitais é destinada à manutenção da capacidade física da empresa.

Considerando essa possibilidade, a Lei das Sociedades por Ações prevê, na seção de Reservas e Retenção de Lucros, a faculdade de as companhias reterem parcela dos lucros prevista em orçamento de capital aprovado pela assembléia geral. Sua constituição visa, primordialmente, justificar o não pagamento de dividendos superiores ao mínimo obrigatório, face às necessidades de recursos da companhia resultantes do seu plano orçamentário (BRASIL, IN CVM $n^{\circ}$ 59/86). Por outro lado, a sua constituição não poderá prejudicar a distribuição do dividendo mínimo obrigatório. Destaque-se ainda que de acordo com a referida instrução normativa, não há uma denominação específica para a conta que cumprirá esse papel; podendo assim, se apresentar como reserva de lucros para expansão, reserva para planos de investimento, etc.

\subsubsection{Reserva de Lucros a Realizar}

Prevista no 197 da Lei $n^{\circ}$ 6.404/76, trata-se de uma reserva destinada a receber o valor do dividendo obrigatório excedente à parcela realizada do lucro líquido; isto é, a parcela de dividendos que, calculada nos termos do 202 da Lei das S/A, exceder a soma dos seguintes valores:

- Resultado positivo da equivalência patrimonial;

- O lucro rendimento ou ganhos líquidos em operações ou contabilização de ativo e passivo pelo valor de mercado, cujo prazo de realização financeira ocorra após o término do exercício social seguinte.

Assim sendo, é facultado às companhias constituir tal reserva (BRAGA e ALMEIDA 2008, apud MIOLA et al, 2011). Todavia, optando por fazê-lo, deverá haver menção em Notas Explicativas, dos parâmetros utilizados pela companhia em função da natureza dos itens componentes do lucro a realizar (BRASIL, IN CVM nº 59/86).

Atingido esse ponto, vale ressaltar a restrição legal de constituição das reservas de lucro - excetuando-se as de incentivos fiscais para contingências e de lucros a realizar - 
quando o saldo das mesmas atingir o valor do Capital Social. Nessas circunstâncias, o excesso deverá ser aplicado na integralização ou aumento do Capital Social, ou na distribuição de dividendos.

Finalmente, cabe destacar a expressa proibição - conforme 198 da Lei das SA - da constituição das reservas estatutária e de retenção de lucros; caso a sua constituição seja prejudicial à distribuição do dividendo mínimo obrigatório.

\subsubsection{Dividendos}

Disciplinada na forma do 202 da Lei das Sociedades por Ações, posteriormente alterada pela Lei $\mathrm{n}^{\circ} 10.303 / 01$, a distribuição de dividendos constitui-se em decisão que envolve muitos outros aspectos relevantes, dentre os quais a continuidade da empresa e a manutenção monetária do capital investido. (PADOVEZE; FREZATTI; BENEDICTO; 1994). Tal filosofia é defendida por Pandolfo e Lima (2011) que argumentam que é necessária atenção ao efetuar a distribuição de lucros para não descapitalizar a empresa e garantir a continuidade do negócio.

Nesse sentido, referidos autores recomendam a análise do caixa da empresa em conjunto com os lucros obtidos em exercícios anteriores bem com aqueles obtidos no resultado do exercício, visando identificar a quantia viável a ser distribuída, bem como a parcela que deverá ser retida. Loss e Sarlo Neto (2003, p.40) explicam que "[a] política de dividendos não é apenas uma decisão sobre o quanto pagar aos acionistas, se tratando também de uma decisão sobre o quanto ficará retido na entidade", bem como os motivos de tal retenção. Pensamento similar é defendido por Ross; Westerfield; Jaffe, citados por Freire et al (2005).

A Lei $\mathrm{n}^{\circ}$ 6.404/76 não fixa um valor a ser destinado para dividendos, ao permitir que a empresa distribua conforme consta no seu estatuto. Entretanto, se não houver sido definido pelo estatuto da companhia, a lei exige que seja destinado o equivalente à metade do lucro líquido diminuído ou acrescido do valor destinado a:

- Reserva Legal

- Reserva para contingência e sua reversão formada em exercícios anteriores e não utilizada.

Além desses, existem outros ajustes a serem realizados conforme 202 da referida lei, dentre os quais se destaca o fato de que os lucros não destinados para as reservas acima elencadas - art. 193 a 197 - deverão ser distribuídos a título de dividendos. Tal determinação constitui-se de uma alteração introduzida pela Lei $\mathrm{n}^{\circ}$ 10.303/01, responsável por alterar diversos quesitos na Lei das Sociedades por Ações.

\section{METODOLOGIA DE PESQUISA}

\subsection{Enquadramento Metodológico}

O presente estudo teve como finalidade verificar o procedimento adotado pelas Cia. Abertas no ramo da construção civil listadas pela Bovespa, na destinação dos lucros após as alterações da Lei 11.638/07 que prevê a nova sistemática de transitoriedade da conta de lucros acumulados.

Quanto aos objetivos este estudo é de natureza exploratória, visando aprofundar as discussões advindas da mudança da Lei quanto à contabilização da destinação do resultado tendo a conta de Lucros acumulados como transitória. As recentes discussões sobre esse aspecto legal buscam subsidiar novas discussões e dar consistência ao tema de amplo interesse contábil. Utilizou os recursos da pesquisa bibliográfica para 
configurar as discussões conceituais e legais pertinentes bem como as de base documental, utilizando para tanto das fontes secundárias publicadas e ou divulgadas em meio eletrônico. A abordagem é de natureza qualitativa, uma vez que ao inferir sobre os aspectos legais buscou-se interpretar os procedimentos adotados pelas empresas analisadas.

\subsection{Procedimento para Revisão da Literatura}

Visando à obtenção de material para compor o referencial teórico deste estudo, foi realizada pesquisa bibliográfica nos 13 (treze) periódicos vinculados aos programas de Pós-Graduação recomendados pelas Capes em Ciências Contábeis e em 4 (quatro) eventos caracterizados como importantes na área da ciência contábil brasileira Congresso USP Controladoria e Contabilidade, ANPCONT, Congresso UFSC de Controladoria e Finanças e Congresso Brasileiro de Contabilidade.

A pesquisa dos artigos selecionados foi realizada através do site dos referidos periódicos e nos anais dos eventos disponíveis on line, por meio de mecanismos de busca - título, resumo ou palavra-chave: Destinação de Lucros, Lei № 11.638/07, Destinação Integral, Reserva de Lucro, Dividendos. A busca efetuada contemplou os anos de 2000 a 2011; se estendendo para a revista Contabilidade e Finanças até o ano de 1994, o que se justifica por estudo bastante relevante na publicação sobre a decisão de distribuição de lucros.

Quanto ao Congresso USP de Controladoria e Contabilidade, faz-se ressalva para o fato de que foram pesquisados os trabalhos apresentados a partir da $4^{a}$ edição, realizada no ano de 2004, uma vez que as edições anteriores não estão disponíveis on line. Vale também mencionar que no caso específico do Congresso UFSC de Controladoria e Contabilidade, a pesquisa foi efetuada no CD ROM das edições do congresso, em virtude de não ter sido constatada a disponibilidade dos anais dos trabalhos apresentados em meio on line.

Nesse processo, foram identificados 20 artigos nos Congressos e 21 artigos nos periódicos. Posteriormente, procedeu-se à leitura dos resumos dos artigos, tendo sido desconsiderados aqueles não relacionados com o tema deste estudo; resultando em 11 artigos posteriormente utilizados para a construção do referencial teórico desta pesquisa.

\subsection{População e Amostra}

O estudo foi realizado com empresas pertencentes ao segmento da Construção Civil listadas na BM\&FBOVESPA. A escolha da população se deu em função do objetivo do trabalho - distribuição dos lucros - e se justifica pelo acentuado aquecimento do setor de construção civil nos anos de 2009, 2010 e 2011, conforme constatado em busca efetuada no sítio eletrônico do Ministério do Trabalho e do Departamento Intersindical de Estatísticas e Estudos SócioEconômicos (DIEESE); especialmente em função da redução da taxa de juros e ampliação do crédito subsidiado - Programa Minha Casa, Minha Vida, do Governo Federal, e ainda em consequência da realização de grandes obras preparatórias para a Copa do Mundo de Futebol de 2014 e dos Jogos Olímpicos do Rio de Janeiro, em 2016.

O mesmo pode ser observado a partir da análise da Demonstração de Resultados divulgada pelas 22 (vinte e duas) empresas listadas nesse segmento. Verificou-se que 18 empresas obtiveram lucro em pelo menos dois dos três períodos abrangidos por este estudo; sendo que uma empresa apresentou prejuízos nos três anos analisados, e que para três das empresas listadas não foi possível constatar o resultado apurado, por não 
terem sido disponibilizados os demonstrativos contábeis. Ressalta-se que, dentre as empresas que obtiveram lucro, uma foi excluída da amostra por não divulgar os dados referentes ao exercício de 2009.

Assim sendo, a amostra foi constituída apenas pelas empresas que obtiveram lucro em pelo menos dois dos três exercícios, perfazendo um total de 17 (dezessete) empresas; ou seja, aproximadamente $80 \%$ da população.

\subsection{Procedimentos para Coleta de Dados}

Para cada um dos objetivos específicos estabelecidos para este estudo, foram propostos diferentes formas de tratamento de dados. Visando alcançar o primeiro objetivo específico - verificar o cumprimento à legislação no que tange ao limite permitido para destinação do resultado - recorreu-se à Demonstração das Mutações do Patrimônio Líquido no intuito de constatar as contas utilizadas pelas empresas para a realização da destinação dos lucros; bem como o montante referente aos exercícios 2009, 2010 e 2011, destinado a cada uma delas.

No mesmo demonstrativo, buscou-se também o valor do Lucro base para destinação a partir do qual foram apurados os limites da conta usada por cada uma das companhias para destinação, com base nos percentuais legalmente previstos e anteriormente abordados quando do referencial teórico. Cumpre mencionar que antes da aplicação dos percentuais sobre o valor do lucro do período, foi subtraído o valor do prejuízo acumulado porventura existente. Os valores permitidos pela lei foram comparados aos valores de destinação efetuados pelas companhias; sendo elaborado um gráfico apresentando a representatividade das empresas que cumprem ou não a legislação.

Para alcançar o segundo objetivo específico - averiguar se as empresas estão respeitando o limite legal de saldo acumulado nas contas recebedoras do lucro do exercício coletou-se nos Balanços Patrimoniais divulgados pelas companhias, o saldo acumulado nas respectivas contas para cada um dos três exercícios. Na sequência, apurou-se o valor de manutenção de saldo conforme delimitado pela legislação societária e também abordado no referencial teórico; sendo então possível ser constatado se as empresas observaram os dispositivos legais, ou desrespeitaram a normatização.

Finalmente, visando verificar a obediência à norma que impede a existência de saldo credor na conta de Lucros Acumulados, foi preciso tão somente localizar tal conta no Balanço Patrimonial referente a cada um dos exercícios para constatar se a mesma apresenta saldo. Destaca-se que essa conta é geralmente apresentada com a conta de Prejuízos Acumulados, recebendo a denominação de Lucros/Prejuízos Acumulados. Os resultados são apresentados num gráfico relacionando quantidade de empresas e a presença ou ausência do saldo credor na conta analisada.

\section{ANÁLISE E DISCUSSÃO DOS RESULTADOS}

Esta seção está dividida em três subseções: na primeira, apresentam-se os resultados da análise do limite de destinação para as contas, identificando se as companhias cumprem ou desrespeitam a legislação; na segunda, verifica-se a obediência aos ditames legais para manutenção de saldo nas contas; e na terceira, verifica-se se a existência ou ausência de saldo credor na conta de lucros acumulados.

\subsection{Limites de Destinação}


Neste item, buscou-se identificar se as empresas cumprem o que é proposto nas normas quando da efetuação da destinação do resultado.

Gráfico 01: Observância aos limites para destinação do resultado.

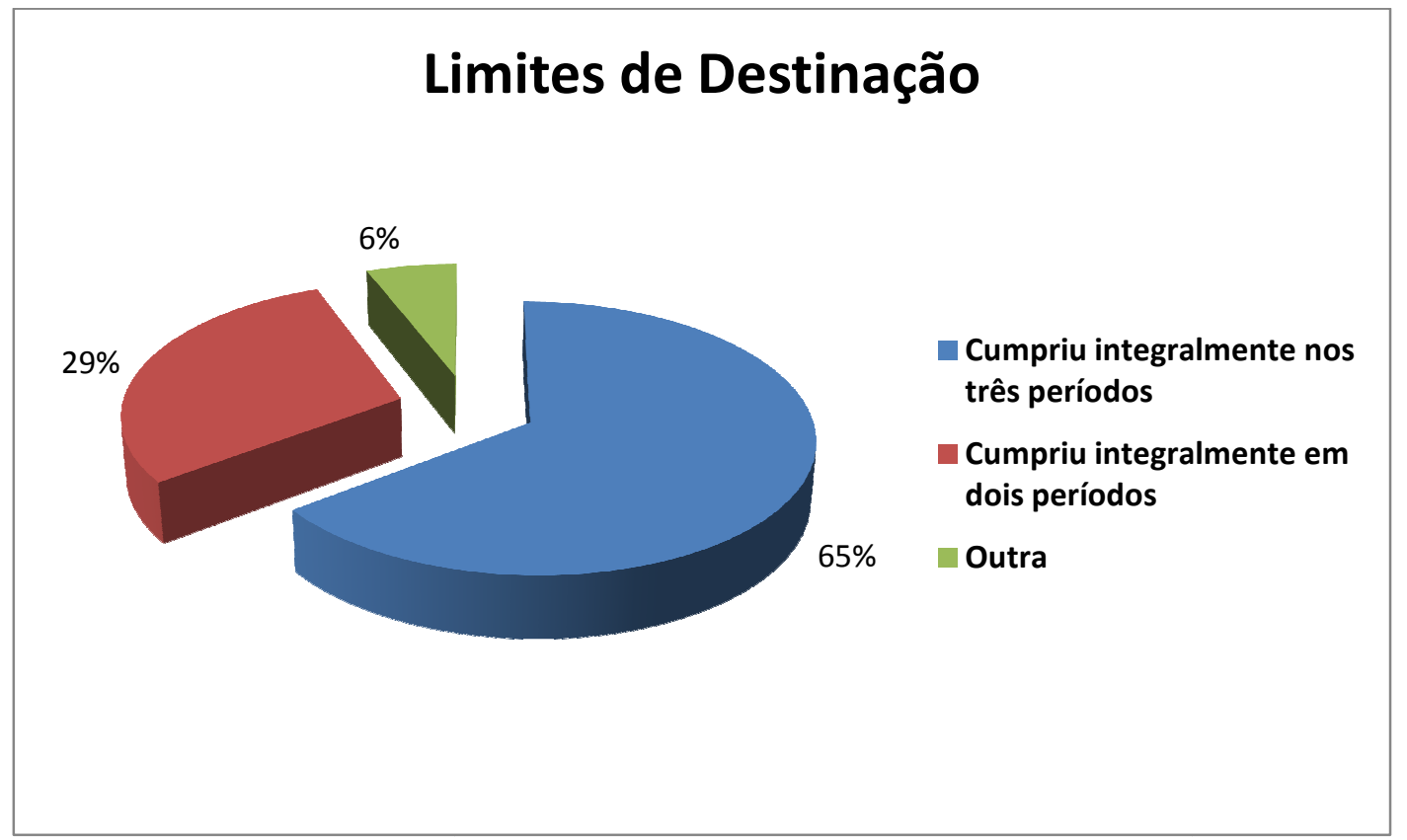

Fonte: Elaborado pelos autores.

A partir dos resultados encontrados observa-se que as limitações imputadas pela legislação para a destinação de lucro às contas estão sendo respeitadas pela maior parte das empresas do segmento da construção civil nos três períodos analisados - 11 das 17 companhias analisadas têm atendido a esse quesito. As maiores incidências de distorções são verificadas nos demonstrativos referentes ao exercício de 2009. Três casos em que o valor destinado à reserva legal não corresponde aos $5 \%$ estabelecidos na legislação, além de três situações em que a quantidade destinada a dividendos não respeita o mínimo legal de $25 \%$. Destaque para a conta de Reserva Estatutária, que recebeu correta destinação quando utilizada. Convém mencionar uma redução gradual de discrepâncias ao longo do período, uma vez que foi constatada apenas uma distorção nas destinações efetuadas no exercício de 2011.

Por meio deste estudo foi possível constatar que as companhias do segmento fazem uso de apenas quatro das sete contas previstas legalmente para a destinação dos lucros, quais sejam: Reserva Legal, Reserva Estatutária, Retenção de Lucros e Dividendos. Considerando ainda o setor de atuação dessas companhias e relacionando aspectos teóricos apresentados neste estudo, é possível afirmar que as contas utilizadas garantem a presença das funções principais do lucro: a remuneração esperada pelo acionista é satisfeita a partir da garantia da mínima destinação para dividendos - realizada corretamente por todas as companhias em pelo menos dois dos três períodos considerados. Da mesma forma, a continuidade das atividades é assegurada a partir da destinação para a Reserva Legal - respeitada em dois dos três exercícios - que de acordo com a legislação visa dar proteção ao credor; bem como por meio da distribuição da maior fatia do lucro para Retenção de Lucros e Reserva Estatutária, com previsão de utilização conforme informado pelas companhias de acordo com a expansão das atividades.

Todavia; cabe uma ressalva com relação à conta de Reserva Estatutária. Embora algumas companhias mencionem a constituição dessa reserva nas Notas Explicativas 
divulgadas; as mesmas a destinem para expansão das atividades da companhia. Essa prática é discutível, uma vez que a legislação prevê que a conta de Retenção de Lucros possa atender a tal finalidade. Conforme a teoria já abordada, as reservas legalmente previstas; ainda que constantes no estatuto da companhia, não se constituem em reservas estatutárias.

\subsection{Limites de Manutenção de Saldo nas Contas Recebedoras do Resultado}

Para a análise do cumprimento às normas que regem a destinação do resultado quanto aos limites legais de manutenção de saldo nas contas, foram comparados os valores constantes do Balanço Patrimonial das companhias com os valores permitidos pela Lei $\mathrm{n}^{\mathrm{o}}$ 6.404/76. Referente à Reserva Legal aplicou-se o $20 \%$ sobre o valor do Capital Social para cada exercício. Buscou-se ainda, verificar se o saldo agregado ao valor das Reservas de Capital não fosse superior a $30 \%$ do Capital Social. Em se tratando da Reserva Estatutária, o limite de saldo é estabelecido pelo estatuto e foi buscado nas Notas Explicativas divulgadas pelas empresas.

Finalmente, foram somados os valores constantes nas contas de Reserva Legal, Reserva Estatutária e Retenção de Lucros, buscando certificar-se de que os mesmos não ultrapassavam o valor do Capital Social. A partir da comparação entre os valores ditados pela legislação e aqueles apresentados pelas companhias, foram obtidos os dados constantes no Gráfico 02:

Gráfico 02: Obediência à manutenção de saldo acumulado nas contas recebedoras do resultado.

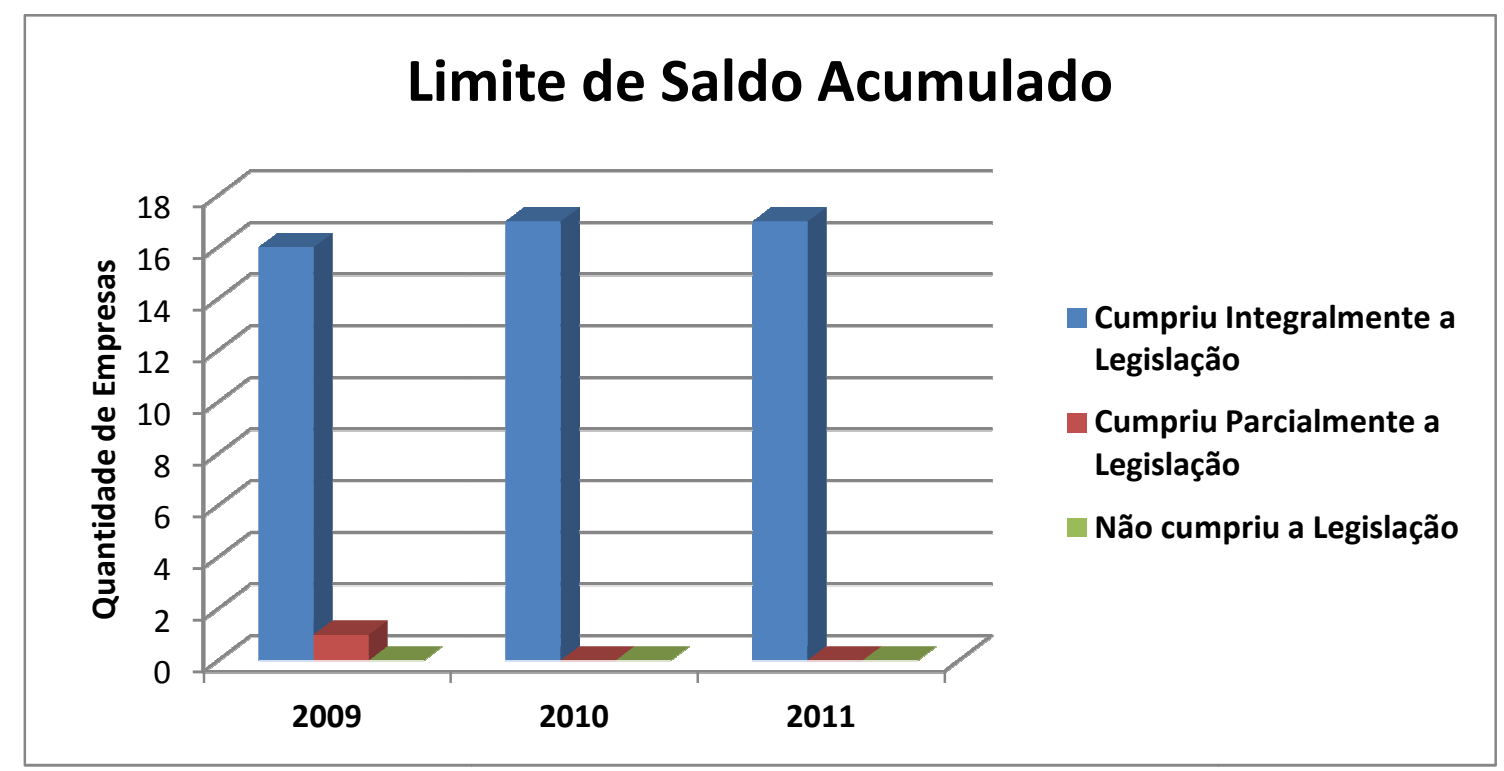

Fonte: Elaborado pelos autores.

Observa-se que a quase totalidade das companhias integrantes do segmento da Construção Civil da BM\&FBOVESPA respeitou o limite definido na Legislação Societária para constituição das contas recebedoras do resultado; de forma que apenas em um exercício, uma das empresas descumpriu parcialmente a legislação permitindo que a soma do valor constante na conta de Reserva Legal e das Reservas de Capital fosse superior aos $30 \%$ do Capital Social. Não foram constatados outros desvios. 
Tal resultado é bastante relevante, pois indica que a companhia está se prevenindo ao reter parte do valor do lucro obtido; sem contudo, prejudicar as demais partes relacionadas por reter indiscriminadamente numerário sem previsão de utilizá-lo.

\subsection{Saldo na Conta de Lucros Acumulados}

Nesta subseção, são apresentados os resultados referentes ao terceiro objetivo específico: presença ou ausência de saldo credor na conta de Lucros Acumulados. Conforme já destacado, para a consecução deste objetivo analisou-se a conta de Lucros/Prejuízos Acumulados no Balanço Patrimonial das companhias, estando os resultados obtidos representados no Gráfico 03.

Gráfico 03: Presença/ausência de saldo credor na conta de Lucros Acumulados.

\section{Saldo Credor em Lucros Acumulados}

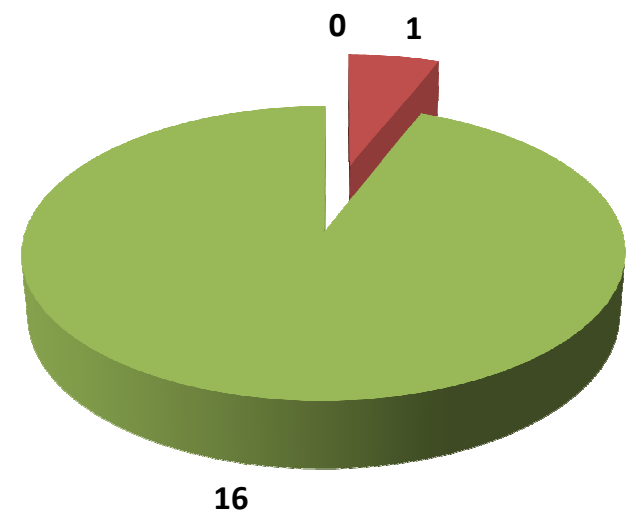

\# Apresentou nos três exercícios

- Em um ou dois exercícios

Em nenhum dos exercícios

16

Fonte: Elaborado pelos autores.

Mais uma vez, o cumprimento às normas fica evidenciado; posto que, no horizonte de análise considerado neste estudo, nove em dez companhias obedecem à norma que impede o uso da conta de lucros acumulados para retenção de numerário. O único desvio encontrado foi no balanço Patrimonial referente ao exercício encerrado em 2011, o que chama a atenção pelo fato da legislação ter concedido tempo para que as empresas se adequassem.

Os resultados encontrados são similares aos obtidos no estudo realizado por Salotti e Santos (2009), que já haviam constatado tendência de queda da utilização da conta de Lucros Acumulados entre os anos de 2001 e 2005. Convém destacar que, para a obtenção dos resultados para este objetivo, foram usados somente os Balanços Patrimoniais referentes aos exercícios encerrados em 2011, apresentando comparativamente os exercícios findos em 2010 e 2009.

Entretanto, se os dados tivessem sido buscados individualmente nos balanços encerrados em cada um dos exercícios, os resultados poderiam ter sido diferentes; visto terem sido constatadas divergências entre as informações do último balanço e aquelas divulgadas em exercícios anteriores - atribuídas; pelos autores, aos ajustes decorrentes do processo de convergência às normas internacionais.

Diante disso, a constatação de que as companhias não estão deixando saldo na conta de Lucros Acumulados; isto é, estão oferecendo uma destinação a todo o lucro por elas 
obtido, é importante. Tal atitude beneficia primeiramente aos sócios - que, conforme constatado em alguns casos no decorrer do estudo, acabam por receber dividendos acima do mínimo obrigatório; o que favorece também agentes externos - como potenciais clientes e fornecedores. Isso porque grande parte do lucro remanescente após as destinações é alocada na conta de Retenção de Lucros para ser posteriormente utilizado na expansão da companhia. Assim sendo, além de cumprir a legislação estão sendo beneficiadas partes relacionadas à companhia.

\section{CONSIDERAÇÕES FINAIS}

No transcorrer deste trabalho discutiu-se sobre a destinação dos lucros e a nova sistemática de transitoriedade da conta de lucros acumulados. A abordagem levou em consideração os aspectos legais que permeiam o assunto, bem como a sua observância por parte das companhias sujeitas à lei das Sociedades por Ações, tendo as companhias listadas no segmento de construção civil da BM\&FBOVESPA, como estudo de caso.

Os resultados demonstram que a legislação está sendo respeitada pelas companhias em pelo menos dois dos três exercícios. Como resultados dos aspectos estudados, foi possível constatar que:

- A maior parte das empresas - em torno de 65\% - cumpre o limite ditado legalmente quando da realização da destinação - aproximando-se de $100 \%$, no caso específico da Reserva Estatutária;

- A legislação é observada pela maioria absoluta das companhias no que diz respeito à manutenção de saldo acumulado nas contas recebedoras do resultado;

- A alteração introduzida pela Lei 11.638/07, que resultou na impossibilidade de saldo credor na conta de lucros acumulados é respeitada por todas as companhias em 2009 e 2010, não sendo observada por apenas uma companhia, durante o exercício de 2011.

Em linhas gerais, os resultados evidenciam que as companhias estão procedendo à destinação dos lucros conforme com os dispositivos legais; e, em consequência disso, há redução na possibilidade de prejuízos para algumas das partes que com elas se relacionam. Conforme abordado anteriormente, a previsão das reservas e da distribuição para dividendos assegura o cumprimento das funções do lucro: satisfação dos proprietários e continuidade das operações.

Convém destacar a dificuldade encontrada pelos autores no que se refere à coleta de dados; que até certo ponto, podem ser apontadas como resultado do processo de convergência às normas internacionais de contabilidade. Dessa forma, foram de grande valia as Notas Explicativas divulgadas pelas companhias, ajudando a esclarecer a política de destinação de cada uma das empresas; bem como os percentuais e a base de cálculo. Dessa forma, foi possível dar consecução ao estudo, obtendo-se assim resultados em resposta ao objetivo maior da pesquisa.

Ponderando todos esses fatores, torna-se imprescindível que a pesquisa aqui empreendida tenha desdobramentos posteriores. Sugere-se como futuros trabalhos: (i) realizar uma comparação da obediência à legislação para destinação dos lucros entre o setor considerado neste estudo e as empresas que apresentam os maiores volumes de lucros da BM\&FBOVESPA; (ii) analisar as causas da não utilização das diversas formas de reservas previstas na lei $\mathrm{n}^{\circ}$ 6.404/76; tendo em vista, conforme constatado neste estudo, que a maioria das empresas utiliza apenas as contas de reserva legal e de retenção de lucros; (iii) analisar a ocorrência de mudanças na política de destinação 
efetuada pelas companhias em função da proibição da existência de saldo credor na conta de Lucros Acumulados.

\section{REFERÊNCIAS}

BRASIL. Lei 6.404, de 15 de dezembro de 1976. Dispõe sobre as Sociedades por Ações. Disponível em: <http://www.planalto.gov.br/ccivil_03/leis/L6404compilada.htm>. Acesso em: 20 jul. 2012.

BRASIL. Lei 10.303, de 31 de outubro de 2001. Altera e acrescenta dispositivos na Lei $\mathrm{n}^{\mathrm{o}}$ 6.404, de 15 de dezembro de 1976, que dispõe sobre as Sociedades por Ações, e na Lei $\mathrm{n}^{\mathrm{0}} 6.385$, de 7 de dezembro de 1976, que dispõe sobre o mercado de valores mobiliários e cria a Comissão de Valores Mobiliários. Disponível em: $<$ http://www.planalto.gov.br/ccivil_03/leis/LEIS_2001/L10303.htm>. Acesso em: 20 jul.2012.

BRASIL. Lei n. 11.638, de 28 de dezembro de 2007. Altera e revoga dispositivos da Lei $\mathrm{n}^{\mathrm{o}}$ 6.404, de 15 de dezembro de 1976, e da Lei $\mathrm{n}^{\mathrm{0}}$ 6.385, de 7 de dezembro de 1976, e estende às sociedades de grande porte disposições relativas à elaboração e divulgação de demonstrações financeiras. Disponível em: <http://www.planalto.gov.br/ccivil_03/_ato2007-2010/2007/lei/111638.htm>. Acesso em: 20 jul. 2012.

COMISSÃO DE VALORES MOBILIÁRIOS. Instrução Normativa n. 59, de 22 de dezembro de 1986. Dispõe sobre a obrigatoriedade de elaboração e publicação da demonstração das mutações do patrimônio líquido pelas companhias abertas. Disponível em: <http://www.cvm.gov.br/asp/cvmwww/atos/exiato.asp?Tipo=I\&File=/inst/inst059.htm> . Acesso em: 15 jul. 2012.

DIEESE. Estudo Setorial da Construção em 2011. Disponível em: < http://www.dieese.org.br/esp/estPesq56ConstrucaoCivil.pdf>. Acesso em 15 jun. 2012.

FACCI, Nilton; MORIBE, Ademir Massahiro. O Problema do Lucro Distribuível. In: Congresso Brasileiro de Contabilidade, 16., 2000, Goiânia. Anais.... Goiânia: CFC, 2000.

FREIRE, Hércules Vander De Lima et al. Dividendos e Lucros anormais: Um estudo das empresas listadas na Bovespa. Revista Contabilidade \& Finanças, São Paulo, v. 39, p.47-67, dez. 2005. Quadrimestral.

FURUTA, Fernanda; BISPO, Jorge De Souza; VIEIRA, Patrícia Dos Santos. Convergência internacional: Nível de Disclosure e impacto de inovações legais sobre o patrimônio líquido e o resultado das grandes empresas instaladas no Brasil. In: Congresso USP de Controladoria e Finanças e Iniciação Científica em Contabilidade, 10., 2010, São Paulo. Anais... São Paulo: USP, 2010. 
LOSS, Lenita; SARLO NETO, Alfredo. Política de dividendos, na prática é importante. Revista Contabilidade \& Finanças, São Paulo, Edição Comemorativa, p.39-53, out. 2003. Quadrimestral.

MIOLA et al. Destinação dos lucros após a lei 11.638/07: um estudo multicaso das empresas do setor de tecnologia de informação, sub setor computadores e equipamentos. In: Congresso UFSC de Controladoria e Finanças e Iniciação Científica em Contabilidade, 4, 2011. Florianópolis, Anais... Florianópolis, UFSC, 2011.

PADOVEZE, Clóvis Luís; FREZATTI, Fábio; BENEDICTO, Gideon Carvalho de. A decisão de distribuição de lucros: alguns aspectos que envolvem essa decisão. Revista Contabilidade e Finanças, São Paulo, 11 ed., jul. 1994.

PANDOLFO, Thaise; LIMA, Emanoel Marcos. Juros sobre o capital próprio ou distribuição de lucros: o que é melhor? In: Congresso Ufsc de Controladoria e Finanças e Iniciação Científica em Contabilidade, 4., 2011, Florianópolis.Anais... . Florianópolis: UFSC, 2011.

PONTE et al. Análise do grau de cumprimento das práticas de divulgação definidas pelo Pronunciamento Técnico CPC 13 no âmbito das companhias abertas. In: Congresso USP Controladoria e Contabilidade, 10., 2010, São Paulo, Anais... São Paulo, USP, 2010.

SALOTTI, Bruno Meireles; SANTOS, Ariovaldo dos. Retenção de Lucros versus Investimentos: As companhias abertas do mercado brasileiro estão cumprindo as normas legais? Revista da Informação Contábil, Recife, v.3, n.4, p.66-80, out-dez. 2009.

SANTOS, Luis Paulo Guimarães Dos et al. Efeito da Lei 11.638/07 sobre o Conservadorismo Condicional das Empresas Listadas BMF\&BOVESPA. In: Congresso USP de Controladoria E Contabilidade, 10., 2010, São Paulo. Anais... . São Paulo: Congresso USP de Controladoria e Contabilidade, 2010. 